\title{
К вопросу о состоянии развития кустарной промышленности Центрального Черноземья в пореформенный период
}

\author{
С.С. Журавлёв, В.А. Григорова \\ Воронежский институт МВД России, \\ Россия, 394065, г. Воронеж, пр-т Патриотов, д. 53 \\ E-mail: zhuravlev310@yandex.ru
}

\begin{abstract}
Аннотация. В статье на примере Центрального-Черноземного региона анализируется состояние развития кустарной промышленности во второй половине XIX века. Авторы проследили динамику роста промыслового населения, исследовали изменение структуры мелкотоварного производства и имущественного положения кустарей. На конкретных примерах из неопубликованных документов проиллюстрировали техническую оснащенность мелких предприятий крестьян. На основе данных земской статистики авторам удалось проанализировать особенности эволюции кустарнопромысловой деятельности населения Центрально-Черноземных губерний. Всесторонний анализ земской статистики пореформенного периода показал, что кустарно-промысловая деятельность, в которой было занято абсолютное большинство жителей Воронежской, Курской, Тамбовской, Орловской губерний к концу XIX века, по темпам роста производства в несколько раз опережала крупную фабрично-заводскую промышленность.
\end{abstract}

Ключевые слова: кустарная промышленность, кустари, предпринимательство, ЦентральноЧерноземный регион, пореформенный период.

Благодарности: работа выполнена при поддержке профессора кафедры социально-гуманитарных, экономических и правовых дисциплин Воронежского института МВД России, доктора исторических наук Григоровой Виктории Александровны.

Для цитирования: Журавлёв С.С., Григорова В.А. 2021. К вопросу о состоянии развития кустарной промышленности Центрального Черноземья в пореформенный период. Via in tempore. История. Политология, 48 (1): 141-149. DOI: 10.52575/2687-0967-2021-48-1-141-149.

\section{On the state of development of the handicraft industry of the Central Chernozem Region in the post-reform period}

\author{
Sergey S. Zhuravlev, Victoria A. Grigorova \\ Voronezh Institute of the Ministry of internal Affairs of Russia, \\ 53 Patriotov Ave., Voronezh, 394065, Russia \\ E-mail: zhuravlev310@yandex.ru
}

\begin{abstract}
The article analyzes the state of development of artisanal industry in the second half of the 19th century using the example of the Central Chernozem Region. The authors followed the growth dynamics of the commercial population, investigated the changes in the structure of small-scale production and the property status of artisans. Based on examples of unpublished documents, the technical equipment of small enterprises of peasants was illustrated. Based on the data of zemstvo statistics, the authors were able to analyze the features of the evolution of handicraft activity of the population of the Central Chernozem provinces. A comprehensive analysis of the zemstvo statistics of the post-reform period showed that the handicraft industry, in which the absolute majority of residents of the Voronezh, Kursk, Tambov, Oryol provinces were employed, by the end of the XIX century, was several times ahead of the large factory industry in terms of production growth.
\end{abstract}


Keywords: handicraft industry, handicraftsmen, entrepreneurship, the Central Chernozem region, the post-reform period.

Acknowledgements: the work was supported by Professor of the Department of Social and Humanitarian, Economic and Legal Disciplines of the Voronezh Institute of the Ministry of Internal Affairs of Russia, Doctor of Historical Sciences Grigorova Victoria Alexandrovna.

For citation: Zhuravlev S.S., Grigorova V.A. 2021. On the state of development of the handicraft industry of the Central Chernozem Region in the post-reform period. Via in tempore. History and political science, 48 (1): 141-149 (in Russian). DOI: 10.52575/2687-0967-2021-48-1-141-149.

\section{Введение}

Исследование локальных аспектов истории кустарной промышленности России в настоящее время выступает актуальной проблемой в исторической науке. В свое время именно на ее базе в регионе формировался предпринимательский слой. Накапливая доход от продажи кустарных изделий, мелкие товаропроизводители при сочетании определенных условий превращались в собственников частных предприятий. Они не имели крупных капиталов, а помощь со стороны государства была непоследовательна и ограничена. При этом их отличала деловая хватка и активность, которая сегодня в контексте преодоления последствий социально-экономического кризиса признается важным условием функционирования государства.

\section{Объекты и методы исследования}

Объектом исследования настоящей статьи выступает кустарный сектор экономики Центрального Черноземья в пореформенный период. В работе были использованы следующие методы исследования: анализ, синтез, историко-сравнительный, историко-генетический. Историко-сравнительный метод позволил проследить динамику развития промыслового населения в отдельных губерниях Центрально-Черноземного региона страны в пореформенный период. Историко-генетический метод позволил проследить изменения, которые происходили в кустарном секторе региональной экономики в пореформенный период.

\section{Результаты и их обсуждение}

Процесс становления и развития кустарной промышленности в России принадлежит к числу дискуссионных тем в отечественной историографии. Основным противоречием до сих пор остается неоднозначная интерпретация научно-теоретических основ мелкотоварного производства. Предметом спора выступала суть понятия - «кустарь». В дореволюционной историографии он трактовался как мелкий товаропроизводитель из низших сословий, не связанный с формой промышленности [Рындзюнский, 1966, с. 72]. Исследователи советского периода указывали на необходимость разграничения домашней промышленности, ремесленного производства и кустарной промышленности. Например, В.И. Ленин, доказывая капитализацию кустарных промыслов, обосновывал связь кустарей с рынком. Кустарем признавался тот товаропроизводитель, который сбывал товар исключительно на базарах и ярмарках [Ленин, 1967, с. 354].

Ориентированность на рынок в качестве основного признака признается и современными учеными: В.А. Григоровой, Н.А. Душковой, А.В. Перепелицыным, М.Д. Карпачёвым, И.Н. Лихорадовой и др. [Перепелицын, 2006, с. 56; Карпачёв, 2012, c. 23; Лихорадова, 2013, с. 18; Григорова, 2017, с. 24; Душкова, 2018, с. 320].

Также предметом спора выступала суть понятия - «кустарная промышленность». В рамках дореволюционной историографии сложилась вполне устойчивая традиция отождествления «кустарной промышленности» с крестьянскими промыслами. Данная точка 
зрения прослеживается в работах А.К. Корсака, А.А. Рыбникова [Корсак, 1861, с. 2; Рыбников, 1922, с. 22].

В отдельных случаях «кустарная промышленность» рассматривается в качестве мелкой семейной организации производства продуктов с целью их дальнейшего сбыта, которая свойственна крестьянскому сословию российского общества и используется ими как подспорье при основном занятии - земледелии [Брокгауз, Ефрон, 1991, с. 121].

Довольно интересную позицию по данному вопросу выразил выдающийся государственный деятель России Н.Х. Бунге. В работе «Полицейское право» автор отметил, что кустарная промышленность представляет собой домашнюю форму производства, которая обслуживала интересы крупных фабрик и заводов как в городской, так и в сельской местности [Бунге, 1869, с. 236].

В историографии российского периода кустарная промышленность трактуется с экономических и юридических позиций. Исследователи поднимают вопросы о наличии подспорного характера промысловой деятельности по отношению к земледелию, о специфике семейной организации труда, о кооперации мелких товаропроизводителей.

В качестве наиболее важной характеристики кустарного производства подчёркивается отсутствие какой-либо законодательной основы осуществления данного вида деятельности. Кроме того, признаётся сословная принадлежность предприятий кустарного типа крестьянству как носителю традиционных, патриархальных устоев российского общества [Ловцова, 2015, с. 8].

Конкретно-исторические аспекты зарождения и эволюции кустарно-промысловой деятельности в российской деревне проанализированы в работах И.Д. Ковальченко, О.Н. Бурдиной, Л.И. Земцова, В.В. Канищева, Б.Н. Миронова [Ковальченко, 1974; Земцов, 1994; Бурдина, 1996; Миронов, 1999; Канищев, 2002].

Анализ различных трактовок позволил сделать вывод, что «кустарная промышленность» относится к особой разновидности мелкой обрабатывающей промышленности, характеризующейся специфическими признаками:

1. Преобладание ручного труда.

2. Организуется, как правило, в форме семейного, домашнего производства.

3. Ориентирована на удовлетворение потребительского спроса населения в товарах массового потребления.

4. Имеет тесную связь с рынком сельскохозяйственной продукции.

5. Не облагается налогом со стороны государства.

6. Применение наемного труда.

На территории Центрального Черноземья кустарная промышленность, сочетавшая в себе все указанные признаки, активное распространение получила в пореформенный период. Социально-экономическая ситуация того времени, нерешенность земельного вопроca, специфика арендных отношений на землю, последствия строительства железных дорог, связанные с расширением рыночных отношений, обуславливали активность обращения крестьян к промысловым занятиям.

Динамика роста промыслового населения в регионе в течение двух последних десятилетий XIX века в Воронежской, Курской, Тамбовской и Орловской губерниях отмечалась в пределах от 1,4 до 13 раз [Григорова, 2017, с. 145].

Масштабы данного процесса были приблизительными, так как при расчете использовались показатели, зафиксированные различными ведомствами - земствами, Губернским статистическим комитетом и другими.

Динамику роста промыслового населения региона в пореформенный период можно представить в виде диаграммы, составленной авторами на основе анализа статистических сведений подворной переписи Воронежской губернии, итогов исследований земств и Губернского статистического комитета, а также данных первой всеобщей переписи населения страны. 
Диаграмма 1 показывает, что в течение двух десятилетий численность людей, занятых промысловой деятельностью, стабильно увеличивалась. Наивысшие показатели роста регистрировались в Орловской губернии, далее - в Тамбовской, Воронежской и Курской губерниях в порядке возрастания.

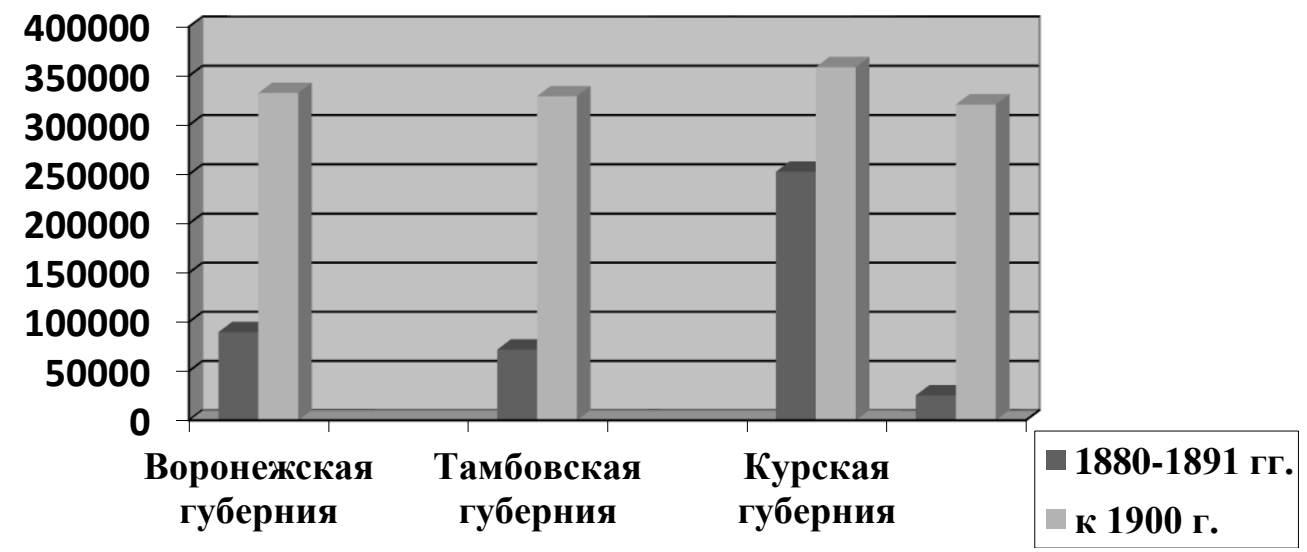

Рис. 1. Динамика роста промыслового населения Центрального Черноземья в конце XIX века [Григорова, 2017, с. 146]

Резкий скачок промыслового населения Орловской губернии на 295677 человек объяснялся особенностями системы землевладения, сложившейся после отмены крепостного права. Большинство крестьян, оказавшись малоземельными, причем зачастую с участками низкого плодородия, вынуждено обращалось к вспомогательным видам деятельности с целью получения какого-либо дохода.

Динамика роста промыслового населения на территории региона сопровождалась различными трансформациями в рамках кустарно-промысловой деятельности, основным среди которых являлось изменение структуры мелкотоварного производства.

В пореформенный период в общей структуре крестьянской кустарной промышленности Центрально-Черноземного региона выделялись предприятия, связанные с обработкой продукции земледелия и животноводства: мукомольное, салотопенное, маслобойное, крупяное, солодовенное и др.

Следующий уровень градации был представлен предприятиями по обработке природного сырья: свечносальное, поташное, кожевенное, химическое, писчебумажное, мыловаренное, кирпичное и другие виды производств [Орлов, 1881, с. 267].

Техническая оснащённость подобных кустарных предприятий, как правило, была скромной. Так, в «Оценочной описи имущества овчинной мастерской жителя села Нижняя Катуховка, Воронежского уезда, Алексея Трофимовича Шеменёва» указано, что принадлежащее ему предприятие было небольших размеров $(3 \times 2,75 \times 1,16$ м), выстроено из сосновых досок, из инструментов в нём числились: коса -1 шт., железный крюк - 1 шт., гребешки - 1 шт., колода -1 шт $^{25}$.

Аналогично был организован паточный завод жителя Новая Усмань Усманской волости Воронежского уезда, крестьянина Андрея Сергеевича Чухвистова. Здание завода было выстроено из кирпича, без окон. Двери, полы и потолок завода изготовлены из сосны. Техническое оснащение представляли котёл из красной меди, предназначенный для варки крахмала, кирпичная печь для котла, стрельчатые весы, комплект чугунных гирь весом в 1, 2, 10, 20 пудов, чан для размолки крахмала ${ }^{26}$.

Прибыль таких предприятий была невысокой и напрямую зависела от технического оснащения и типа производства. В частности, маслобойный завод жителя села Желан-

${ }^{25}$ Государственный Архив Воронежской Области (далее ГАВО). Ф. И-20. Оп. 1. Д. 6116. Л. 1-4.

${ }^{26}$ ГАВО. Ф. И-20. ОП. 1. Д. 7871. Л. 1-6. 
ное Михайловской волости Бобровского уезда Губина Михаила ежегодно приносил своему владельцу доход в сумме 53 рубля 36 копеек ${ }^{27}$.

Важно заметить, что промышленные заведения мелких товаропроизводителей распределялись в регионе неравномерно. Например, в Воронежской губернии 8 мельниц и 6 крупорушек насчитывалось в пределах Новопокровской волости Бобровского уезда. В Богучарском уезде регистрировалось 3647 мельниц и 91 крупорушка. В Коротоякском уезде было 1005 ветряных мельниц, 59 водяных мельниц и 120 крупорушек ${ }^{28}$.

Подобный разброс промышленных заведений отмечался и в Тамбовской губернии, где неравномерность была обусловлена экономическими и природно-географическими особенностями.

Последствием формирования новой структуры мелкотоварного производства на территории региона явилось улучшение имущественного положения кустарей, связанное с процессом формирования частной собственности крестьян в виде надельной земли, инвентаря, рабочего скота и промышленных предприятий.

Определенную роль в данном процессе играли меры государственной политики в отношении кустарного производства, одной из которых являлось использование элементов дифференцированного подхода к налогообложению. Так, ремесленные и фабричные предприятия, а также сельскохозяйственные заведения кустарного типа: кирпичные заводы, лесопилки, маслобойни и другие виды производств, располагавшиеся на частной территории либо на арендуемых земельных угодьях, освобождались от уплаты налоговых пошлин в том случае, если численность рабочих на них была менее 16 человек, а при производстве продукции машины и другое оборудование, приводимое в действие паром, не использовались [Положение о пошлинах за право торговли и других промыслов со всеми позднейшими изменениями и дополнениями, с. 7].

Важное место в деятельности местных органов власти отводилось мероприятиям по поддержке промыслов. Данные меры сводились к финансированию местных кустарных производств со стороны государства, к распространению сельскохозяйственных и производственных знаний среди местного крестьянского населения, устройству сельскохозяйственных выставок кустарных изделий, устройству сельскохозяйственных складов и т. д. Все вышеуказанные позиции способствовали активизации хозяйственной активности крестьянского населения в условиях формирующихся рыночных отношений.

Не исключением были и земские органы Воронежской губернии. Так, для усовершенствования производственных знаний среди местного населения, занимавшегося плетением кружева, в Задонском уезде Воронежской губернии в селе Пальны в 1880-е гг. была организована практическая школа кружевниц, в которой обучали плетению кружев, рисованию и составлению сколков, а также принимали заказы и скупали кружева у местного населения. Данная школа имела несколько отделений, располагавшихся по всему уезду. Школа кружевниц финансировалась за счёт средств Министерства земледелия и государственных имуществ ${ }^{29}$.

В том же Задонском уезде Воронежской губернии при посредничестве земских органов были выработаны меры поддержки производителей сельскохозяйственных машин и орудий труда. Данные меры поддержки сводились к следующему:

1. Обеспечено взаимодействие между местными мастерами и Задонской школой ремесленных учеников, которая занималась изготовлением валов для тех крестьян, которые приобретали недоработанные детали.

2. Кустарям была оказана помощь в реализации готовой продукции. Организованные по инициативе земств сельскохозяйственные склады скупали за наличные деньги

\footnotetext{
${ }^{27}$ ГАВО. Ф. И-20. Оп. 1. Д. 5895. Л. 7.

${ }^{28}$ ГАВО, Ф. И-21. Оп. 1. Д. 1146. Л. 10

${ }^{29}$ ГАВО. Ф. И-20. Оп. 1. Д. 4561. Л. 11.
} 
у кустаря готовую продукцию и продавали её покупателю в кредит с начислением небольших процентов в пользу склада.

3. Были организованы выставки кустарной продукции с целью популяризации технических знаний среди местных мастеров. Авторы лучших изобретений имели право получить от государства премию в размере 15 рублей.

4. При поддержке земств местные сельскохозяйственные склады снабжали кустарей дешёвым материалом и сырьём и т. д. ${ }^{30}$

В с. Конь-Колодезь Задонского уезда Воронежской губернии в пореформенный период функционировала сельскохозяйственная школа, которая занималась профессиональной подготовкой кустарей. Данное учебное заведение выступало своеобразным просветительским центром по распространению сельскохозяйственных знаний среди местного населения. В начале 1890-х гг. при поддержке земств при школе были созданы предприятия по переработке сельскохозяйственной продукции: сыроваренные, маслоделательные, молочные, крахмальные, маслобойные заводы. Сырьё для предприятий школа скупала у местных производителей в обход скупщикам. Готовая продукция при содействии школы сбывалась на рынках губернии и за её пределами.

Деятельность данной школы положительно сказалась на хозяйственном развитии уезда. Так, например, в 1892 году при поддержке школы местные крестьяне заложили до 8000 огородов, на которых с целью последующей продажи выращивали бахчи, огурцы, помидоры, капусту и т. д. ${ }^{31}$

\section{Заключение}

Таким образом, на территории Центрально-Черноземного региона в пореформенный период отмечался рост численности промыслового населения и активизация промысловой деятельности крестьян. Мелкие предприниматели, вовлеченные в производство и товарно-денежные отношения, применявшие наёмную рабочую силу на предприятиях кустарного типа, принимали деятельное участие в процессе формирования капиталистической экономики Российской империи. В итоге в годы форсированного развития промышленного способа производства в ходе индустриализации промыслы сохранились, несмотря на конкуренцию развивавшегося крупного производства. И уже к концу XIX века в регионе отмечалось практически пятикратное превосходство занятости кустарей в мелких промыслах по сравнению с фабрично-заводской промышленностью.

\section{Благодарности}

Автор выражает глубокую благодарность научному руководителю, доктору исторических наук, профессору кафедры социально-гуманитарных, экономических и правовых дисциплин Воронежского института МВД России В.А. Григоровой.

\section{Список литературы}

1. Бунге Н.Х. 1873. Полицейское право. Ч. 2. Киев, Издательство «Университетской типографии», 356.

2. Бурдина О.Н. 1996. Крестьяне-дарственники в России. 1861-1907. М.: Наука, 567.

3. Григорова В.А. 2017. Кустарные промыслы Центрального Черноземья на пути модернизации (вторая половина XIX - начало XX века). Воронеж, ФГБОУ ВО «Воронежский государственный технический университет», 291.

4. Душкова Н.А. 2018. Исторический опыт государственного управления кустарной промышленностью Центрального Черноземья (вторая половина XIX - начало XX века). Былые годы, 47: 319-327.

${ }^{30}$ ГАВО. Ф. И-20. Оп. 1. Д. 4561. Л. 17-18.

${ }^{31}$ ГАВО. Ф. И-20. Оп. 1. Д. 2015. Л. 3-5. 
5. Зозуля О.А. 2015. Российское государство, земство и кустари на рубеже XIX-XX вв.: формирование системы взаимоотношений. Лесной вестник, 4: 129-137.

6. Земцов Л.И. 1994. Крестьяне Центрально-Черноземного района на рубеже $\mathrm{XIX-XX} \mathrm{веков.} \mathrm{Проблемы} \mathrm{исторической} \mathrm{демографии} \mathrm{и} \mathrm{исторической} \mathrm{географии} \mathrm{Центрального}$ Черноземья. Курск, Издательство Курского государственного педагогического института, 342.

7. Корсак А.О. 1861. О формах промышленности вообще и о значении домашнего производства (кустарной и домашней промышленности) в Западной Европе и России. М., Типография Грачева и $\mathrm{K}^{\circ}, 310$.

8. Карпачев М.Д. 2012. Роль неземледельческих промыслов в жизни крестьянства Воронежской губернии в начале XX века. Вестник Воронежского Государственного Университета, 2: 65-74.

9. Канищев В.В. 2002. Естественноисторические условия модернизации аграрного общества. Тамбовская губерния, XIX-XX вв. Некоторые итоги и проблемы изучения. Социальная история российской провинции в контексте модернизации аграрного общества в XVII-XX вв.: материалы международной конференции. Тамбов, 236.

10. Ковальченко И.Д. 1974. Всероссийский аграрный рынок, XVIII - начало XX в. Опыт количественного анализа. М., Наука, 451.

11. Кустарная промышленность. Энциклопедический словарь. Под ред. Ф.А. Брокгауза, И.А. Ефрона. М., «Терра»: 121.

12. Положение о пошлинах за право торговли и других промыслов со всеми позднейшими изменениями и дополнениями. Харьков, А.В. Скалон, 82.

13. Ловцова М.С. 2015. Промыслы крестьянства аграрного региона в ракурсе социального развития (Тамбовская губерния 1870-1908 гг.). Вестник ТГУ, 20: 105-113.

14. Ленин В.И. 1985. Полное собрание сочинений. Т. 3. Развитие капитализма в России. М., Издательство политической литературы, 832.

15. Лихорадова И.Н. 2013. Формирование групп строительных рабочих и рабочих гужевого транспорта в Воронежской губернии в пореформенный период. Научный вестник Воронежского Государственного Архитектурно-Строительного Университета, 2: 18-26.

16. Миронов Б.Н. 1999. Социальная история России периода империи (XVIII - начало XX в.). СПб., Изд-во «Дмитрий Буланин», 267.

17. Орлов П.А. 1881.Указатель фабрик и заводов Европейской России с царством Польским и Вел. кн. Финляндским: материалы для фабрично-заводской статистики. СПб., Типография братьев Пантелеевых, 753.

18. Перепелицын А.В. 2006. Крестьянская промышленность Центрального Черноземья России в 60-90-е годы XIX века. Вестник Воронежского Государственного Университета, 1: 56-64.

19. Рыбников А.А. 1922. Мелкая промышленность и ее роль в восстановлении русского народного хозяйства. М., Кооперативное Издательство, 52.

20. Рындзюнский П.Г. 1966. Крестьянская промышленность в пореформенной России (60-80 гг. XIX в.). М., Наука, 261.

\section{References}

1. Bunge N.H. 1873. Policejskoe pravo [Police law]. P.2. Kiev, Izdatel'stvo «Universitetskoj tipografii», 356 .

2. Burdina O.N. 1996. Krest'yane-darstvenniki v Rossii. 1861-1907 [Peasants-donators in Russia. 1861-1907]. M., Nauka, 567.

3. Grigorova V.A. 2017. Kustarnye promysly Central'nogo Chernozem'ya na puti modernizacii (vtoraya polovina XIX - nachalo XX veka) [Handicrafts of the Central Chernozem region on the way of modernization (the second half of the XIX - the beginning of the XX century)]. Voronezh, GBOU VO «Voronezhskij gosudarstvennyj tekhnicheskij universitet», 291.

4. Dushkova N.A. 2018. Istoricheskij opyt gosudarstvennogo upravleniya kustarnoj promyshlennost'yu Central'nogo Chernozem'ya (vtoraya polovina XIX - nachalo XX veka) [Historical experience of state management of the handicraft industry of the Central Chernozem region (the second half of the XIX - the beginning of the XX century)]. Bylye gody, 47: 319-327. 
5. Zozulja O.A. 2015. Rossijskoe gosudarstvo, zemstvo i kustari na rubezhe XIX-XX vv.: formirovanie sistemy vzaimootnoshenij [The Russian State, the Zemstvo and the Artisans at the Turn of the XIX-XX centuries: the formation of a system of relations]. Lesnoj vestnik, 4: 129-137.

6. Zemcov L.I. 1994. Krest'yane Central'no-Chernozemnogo rajona na rubezhe XIX-XX vekov. Problemy istoricheskoj demografii i istoricheskoj geografii Central'nogo Chernozem'ya [Peasants of the Central Chernozem region at the turn of the XIX-XX centuries. Problems of historical demography and historical geography of the Central Chernozem region]. Kursk, Izdatel'stvo Kurskogo gosudarstvennogo pedagogicheskogo instituta, 342.

7. Korsak A.O. 1861. O formah promyshlennosti voobshhe i o znachenii domashnego proizvodstva (kustarnoj i domashnej promyshlennosti) v Zapadnoj Evrope i Rossii [On the forms of industry in general and on the importance of home production (cottage and home industry) in Western Europe and Russia]. M., Tipografiya Gracheva i K 310.

8. Karpachev M.D. 2012. Rol' nezemledel'cheskih promyslov v zhizni krest'yanstva Voronezhskoj gubernii v nachale XX veka [The role of non-agricultural crafts in the life of the peasantry of the Voronezh Province at the beginning of the XX century]. Vestnik Voronezhskogo Gosudarstvennogo Universiteta, 2: 65-74.

9. Kanishchev V.V. 2002. Estestvennoistoricheskie usloviya modernizacii agrarnogo obshchestva. Tambovskaya guberniya, XIX-XX vv. Nekotorye itogi i problemy izucheniya [Naturalhistorical conditions of modernization of the agrarian society. Tambov province, XIX-XX centuries. Some results and problems of the study]. Social'naya istoriya rossijskoj provincii $\mathrm{v}$ kontekste modernizacii agrarnogo obshchestva v XVII-XX vv.: materialy mezhdunarodnoj konferencii. Tambov, 236.

10. Koval'chenko I.D. 1974. Vserossijskij agrarnyj rynok, XVIII - nachalo XX v. Opyt kolichestvennogo analiza [All-Russian agricultural market, XVIII - early XX century. Experience in quantitative analysis]. M., Nauka, 451.

11. Kustarnaya promyshlennost' [Cottage industry]. Enciklopedicheskij slovar'. Pod red. F.A. Brokgauza, I.A. Efrona. M., «Terra»: 121.

12. Polozhenie o poshlinah za pravo torgovli i drugih promyslov so vsemi pozdnejshimi izmeneniyami i dopolneniyami [Regulation on duties for the right to trade and other Crafts with all later amendments and additions]. Har'kov, A.V. Skalon, 82.

13. Lovcova, M.S. 2015. Promysly krest'janstva agrarnogo regiona v rakurse social'nogo razvitija (Tambovskaja gubernija 1870-1908 gg.) [Crafts of the peasantry of the agrarian region in the perspective of social development (Tambov province 1870-1908)]. Vestnik TGU, 20: 105-113.

14. Lenin V.I. 1985. Polnoe sobranie sochinenij. T. 3. Razvitie kapitalizma v Rossii [The complete collection of works. The development of capitalism in Russia]. M, Izdatel'stvo politicheskoj literatury, 678.

15. Lihoradova I.N. 2013. Formirovanie grupp stroitel'nyh rabochih i rabochih guzhevogo transporta $\mathrm{v}$ Voronezhskoj gubernii v poreformennyj period [Formation of groups of construction workers and horse-drawn transport workers in the Voronezh Province in the post-reform period]. Nauchnyj vestnik Voronezhskogo Gosudarstvennogo Arhitekturno-Stroitel'nogo Universiteta, 2: 18-26.

16. Mironov B.N. 1999. Social'naya istoriya Rossii perioda imperii (XVIII - nachalo XX v.) [Social History of Russia during the Imperial period (XVIII - early XX century)]. SPb.: Izd-vo «Dmitrij Bulanin», 267.

17. Orlov P.A. 1881. Ukazatel' fabrik i zavodov Evropejskoj Rossii s carstvom Pol'skim i Vel. kn. Finlyandskim: materialy dlya fabrichno-zavodskoj statistiki [Index of factories and factories of European Russia with the Kingdom of Poland and the Grand Duchy of Finland: materials for factory statistics]. SPb., Tipografiya brat'ev Panteleevyh, 753.

18. Perepelicyn A.V. 2006. Krest'janskaja promyshlennost' Central'nogo Chernozem'ja Rossii v 60-90-e gody XIX veka [Peasant industry of the Central Chernozem Region of Russia in the 60-90s of the XIX century]. Vestnik Voronezhskogo Gosudarstvennogo Universiteta, 1: 56-64.

19. Rybnikov A.A. 1922. Melkaja promyshlennost' i ee rol' v vosstanovlenii russkogo narodnogo hozjajstva [Small-scale industry and its Role in the Restoration of the Russian National Economy]. M., Kooperativnoe Izdatel'stvo, 52.

20. Ryndzjunskij P.G. 1966. Krest'janskaja promyshlennost' v poreformennoj Rossii (60-80 gg. XIX v.) [Peasant industry in Post-Reform Russia (60-80 years of the XIX century)]. M., Nauka, 261. 
ИНФОРМАЦИЯ ОБ АВТОРАХ

Журавлёв Сергей Сергеевич, преподаватель кафедры экономических социально-гуманитарных, и правовых дисциплин Воронежского института МВД России, г. Воронеж, Россия

Григорова Виктория Александровна, Victoria A. Grigorova, professor of the профессор кафедры социально-гуманитарных, экономических и правовых дисциплин Воронежского института МВД России, г. Воронеж, Россия

\section{INFORMATION ABOUT THE AUTHORS}

Sergey S. Zhuravlev, Lecturer, Department of Social and Humanitarian, Economic and Legal Disciplines, Voronezh Institute of the Ministry of Internal Affairs of Russia, Voronezh, Russia Department of Social and Humanitarian, Economic and Legal Disciplines, Voronezh Institute of the Ministry of Internal Affairs of Russia, Voronezh, Russia 